\title{
A VALUES-LED PLANNING APPROACH FOR SUSTAINABLE LAND USE AND DEVELOPMENT
}

\author{
Armands AUZIN̦Š1, Jānis VIESTURS ${ }^{2}$ \\ ${ }^{1,2}$ Institute of Civil Engineering and Real Estate Economics, Riga Technical University, \\ 6 Kalnciema Street, Riga, LV-1048, Latvia \\ Corresponding author e-mail: armands.auzins@rtu.lv
}

\begin{abstract}
The creation of positive synergy in managing land-related resources if exploring the territorial capabilities, threats and opportunities, e.g. the effects of urban expansion, multi-functionality of land use, internalisation of negative externalities and challenges of a city agglomeration, causes primary necessity for the modern society. The study is concerned with the conceptual background and feasibility aspects of values-led planning (VLP) approach to be introduced into land management practice by capitalising first of all on comparative analysis of dynamic spatial planning systems and planning cultures. Finally, it is argued that the implementation of new planning approach within proposed framework would lead towards improved land use policies and better territorial governance, developing more inclusive and resilient territories for the benefit of a society.
\end{abstract}

Keywords: Land use, planning cultures, spatial planning systems, sustainable development, values-led planning.

\section{INTRODUCTION}

It is essential to promote more competitive economics with higher employment level and to implement deliberative migration policy in Europe considering the conditions of market globalization and the impact of high-tech on sustainable spatial development. Nowadays, successful investors/developers, when planning to allocate some business within a territory, look further functional zoning and even suitable transportation network and available engineering infrastructure, as they seek for valuable and available resources, e.g. enough quantity and quality of both natural and man-made resources as well as skilled enough local human resources. Sustainability aspects should be attributed to the challenges and issues pertaining to intensification of land use - how to manage a growing pressure of human needs, e.g. food, resource exploitation, well-being, while at the same time minimizing the impact on the environment, e.g. ecosystems liveability, biodiversity, resource renewability, eco-services? 'Sustainable intensification' is a suggested but vague term that needs to be clarified through land use policies (Petersen \& Snapp, 2015), however, it can be applied to meet the mentioned challenges and issues. The potential for further spatial development should be assessed and then supported by binding decisions. 
Decision-making needs to be backed with facts and analysis through empirical evidence, i.e. 'measuring' that is discussed enough in a collaborative way.

Larsson (2010), when discussing land management scope as a public policy and focusing on means and methods to develop and improve land management, points to important limitations and considers the activities of public authorities, urban development and efficiency measures as topical issues. Spatial planning as a land use and development control system in Europe mainly follows comprehensive integrated and participatory approaches, and locus of power towards decentralisation can be observed there. However, the local governments have to consider the national and regional priorities and interests acknowledged by respective strategies as guidelines for sustainable development planning. Considering the relative roles of both public and private sector in planning, on the one hand, the 'public-led planning' dominates developing comprehensive plans, but, on the other hand, the 'market-led planning' dominates initiating land use changes and developing detailed plans. A 'values-led planning' (VLP) approach would contribute with, so to say, 'valuing and planning-implementing' concept and consequent principles towards balancing both interests nature/landscape protection and new development. Some relevant publications indicate to meaningful land management policies (Larsson, 2010; Randolph, 2012) and changes in spatial planning systems and practices in Europe (Faludi, 2008; Reimer, Getimis \& Blotevogel, 2014; ESPON, n.d., a). Thus, the analysed practices and their continuity emphasise quite challenging issues calling for more integrated, participatory and strategic planning approach and contribute to this topical research regarding the development of VLP approach to be implemented for improving land use and spatial development.

The aim of the study is to explore and discuss the conceptual background and feasibility of VLP approach to be introduced into land management practice by capitalising first of all on comparative analysis of dynamic spatial planning systems and planning cultures.

A framework based on consolidated new knowledge from comparative studies, which imply stakeholders' experience and empirical evidence helps better understand and guide preconditions for introducing VLP approach. Analytical work to explore various spatial planning systems and practices, its step-by-step transformations and continuity indications has been done in the research. The synergy from applying various planning policies and approaches has been observed by review of scientific literature and using dynamic and comparative analysis and synthesis techniques.

\section{VARIOUS VIEWS AND REASONABLE FOCUS OUTLINE OF SPATIAL PLANNING}

Land management as a part of management science itself involves multidisciplinary aspects, because it relates to activities of various stakeholders, who participate and influence decision-making, i.e. regarding land use planning and spatial development at local governmental (municipality) level. The domain of land management has been found in 'institutional economics' (Auziņš, 2013), 
therefore this field leads to key issues on how decision-making influences the usage effectiveness of land-related resources. Considering the scope of land management, it is reasonable to explore in details the planning domain as 'publicly controlled planning' (Larsson, 2010, pp. 3-5). Thus, spatial planning may more appropriately be concerned with planning of development, involving substantial changes and responding to these changes. Accordingly, the principal aim of planning leads to possible and tangible solutions for identified needs and problems to analyse and evaluate these solutions before binding decisions are made and implementation is carried out (Larsson, 2010, pp. 32-37). In general, the meaningful reason for publicly controlled planning is rational spatial development. However, this development should be supported with increasing knowledge rather than providing planning that satisfies market-oriented forces through 'instrumental planning view'. 'Rational planning view' supports an optimal decision according to the planner's preferred values, considering uncertainties, circumstances and alternatives. In reality, the rational reasoning may partly be replaced by intuition or personal preferences, however, it needs to be discussed among stakeholders and based on assessments. Rationality calculations and evaluations in a formal sense may replace informal assumptions and estimations as well as political and other considerations (Larsson, 2010, pp. 38-40). Rational planning as an etalon should be taken to diminish instrumental view's impact and political decisions based on 'personal commitment', which often dominate over systems approach in planning. For this reason the assessment of implementation of land use plans could help promote good land management practice in constructive and sufficiently professional way.

Some international comparative studies of spatial planning systems were carried out to identify variations of institutional settings and artefacts in selected European countries (CEC, 1997; Larsson, 2006; COMMIN, 2007). Thus, comparison was carried out to consider the degree of centralisation, coordination, planning types and levels, statutory requirements or guidelines, participation and citizen influence, private interests, right to appeal and other aspects. In general, such comparative analysis reflects on motives of public planning and control. However, protection of productivity, preservation of environment and cultural heritage as well as integration of public-private participation may be seen as main formulated planning goals (Larsson, 2006, p. 8). It is also recognised that the right to influence development and environmental considerations should be regulated by statutory rules, plans and municipalities (Larsson, 2006, p. 19).

Notwithstanding, spatial planning as such is subject to constant pressure to adapt (Reimer et. al., 2014). Recent comparative study delineates the coexistence of continuity and change and of convergence and divergence with regard to spatial planning practices across Europe. It underlines the specific and content-dependent variety and disparateness of planning transformation, focusing on: (1) the main objectives of the changes, (2) the driving forces behind these changes and the main phases and turning points, (3) the main-agenda-setting actors, and (4) different planning modes and tools reflected in different "policy and planning styles". The ESPON 2020 Cooperation Programme recently initiated the applied research on comparative analysis of territorial governance and spatial planning 
systems in Europe (ESPON, n. d., b). This still on-going comparative study addresses the following issues: (1) observation of changes in territorial governance and spatial planning systems and policies across Europe over the past 15 years, (2) feasibility of attributing these changes to the influence of macrolevel EU directives and policies, (3) identification of best-practices for crossfertilisation of spatial and territorial development policies with EU Cohesion Policy, and (4) the way how national/regional spatial and territorial development policy perspectives can be better reflected in the Cohesion Policy and other policies at the EU scale (ESPON, n. d., b). The objectives and outcomes of these and some other studies quite clearly indicate to discourse and feasibility aspects to discuss and introduce a VLP approach at least in Europe's agenda for improving land use management.

\section{PROPOSED FRAMEWORK TO IMPROVE LAND USE AND SPATIAL DEVELOPMENT PRACTICE}

From comparative analysis of case studies of 12 spatial planning systems and practices across Europe significant changes have been recognised at least since 1990s (Reimer et. al., 2014). The research was based on a systematic and methodological framework and focused on five dimensions of change: (1) scope and objectives, (2) modes and tools, (3) scale(s), (4) actors and networks, and (5) policy and planning styles. Thus, the methodological framework basically referred to the comparative analysis of spatial planning at meso level (national planning system), however it extended both to the macro level (challenges and driving forces) and to the micro level (planning practices) (Reimer et. al., 2014, p. 13). The comparative analysis emphasised spatial planning research in the way it gains essential evidence-based knowledge through multiple trajectories of change. The influence of 'Europeanization' (Faludi, 2008) on spatial planning systems, policies and practices has been considered in the research as well.

The study distinguished between a planning system perspective and a planning culture (practice) perspective, and discussed convergence and divergence of planning systems and practices rather than provided 'classic' comparative analysis performing 'static' comparisons. It was argued in the study that planning practices inherent to the system cannot be drawn from a comparison of legal-administrative framework conditions alone (Reimer et. al., 2014, p. 3). Comparative analysis of planning systems at one scale (national/local) remains static and does not allow gaining understanding of the on-going transformations of those systems (Reimer et. al., 2014, p. 4). Planning culture has sometimes been seen as equivalent to the values, attitudes, mind-sets and routines shared by those taking part in planning (Fürst, 2009). It seems rather obvious that when researching planning systems as an object, the requirement for new theoretical, conceptual and methodological approaches towards planning cultures appears. Reimer \& Blotevogel (2012) interpreted planning systems as "dynamic institutional technologies, which define corridors of action for planning practice, which may, however, nonetheless display a good deal of variability" (Reimer et. al. 2014, p. 4). Therefore, an integrated analytical approach has been chosen, which focused on: (1) 
institutional settings and (2) actors of change that encompasses different spatial tiers - at macro, meso and micro levels (Reimer et. al. 2014, p. 8). A question here could be asked - can other approaches, e.g. VLP, adapt to those?

A multi-scalar analytical framework for comparative spatial planning research characterised adaptive capacities on the meso level and designed planning systems between rigidity and flexibility (Reimer et. al., 2014, pp.9-11). Janin Rivolin (2012) distinguished between four dimensions within a planning system: (1) discourses that show "the prevalence of certain ideas, concepts and arguments in the frame of spatial planning", (2) structures that involve "the overall set of constitutional and legal provisions allowing and ruling the operations of the planning system", (3) tools that besides classical plans include also "control devices, monitoring and evaluation procedures as well as various forms of economic incentives", and (4) planning practices that can be identified through empirical case studies (Janin Rivolin, 2012, p. 71). Based on the above research, the framework of transformation of spatial planning systems is proposed (Fig. 1).

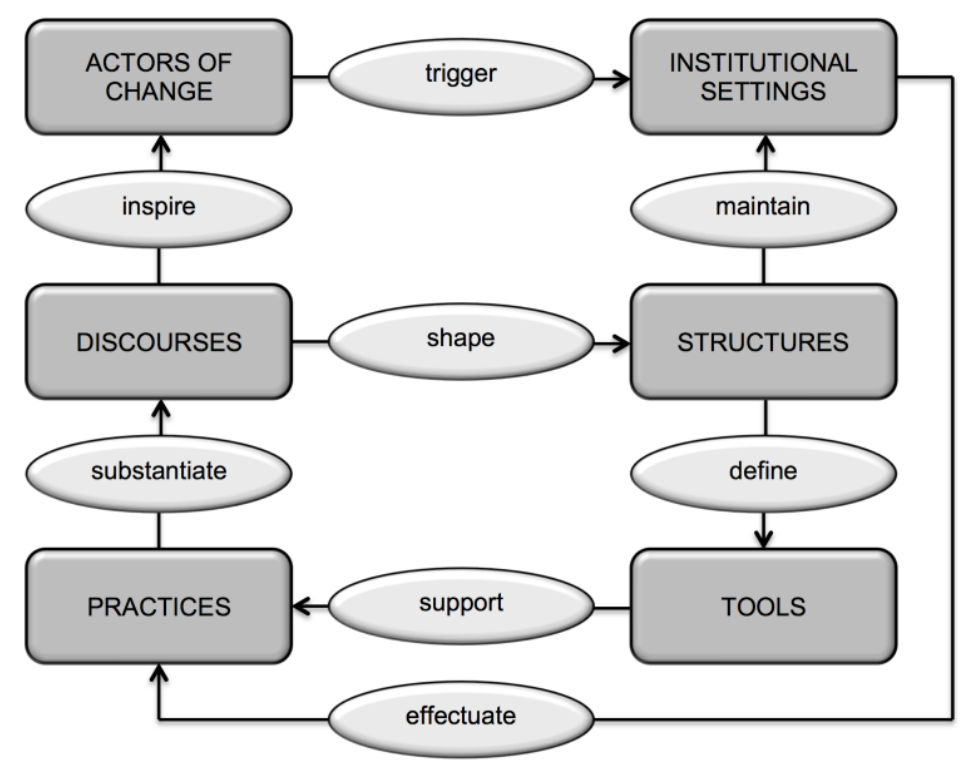

Fig. 1. The framework of the transformation of spatial planning systems [Based on the studies of (Janin Rivolin, 2012; Reimer et. al., 2014)].

All six elements of the framework in Fig. 1 influence the transformation process in the scope of spatial planning. It is recognised that "structures" as basically organisational formations through "tools" provide necessary guidance to improve "practices", but in the similar way "practices" due to recognised "discourses" promote development of "structures". Prevailing "discourses" give reason or 'drive for challenge' the "actors of change", thus give some acknowledgement to the proper "institutional settings", but at the same time "discourses" through appropriate "structures" also make some adjustment to these settings. Accordingly, properly arranged "institutional settings" should provide more effective regulations to improve planning practices. 
Important findings regarding the studies on planning cultures and transformation of spatial planning systems from comparative analysis, which have been described above in this paper, lead to their synthesis. The framework of the transformation (Fig. 1) is proposed to conceptualise the introduction of VLP approach. Accordingly, spatial planning practices and thus land use and development should be improved.

\section{TOWARDS INDRODUCTION OF VALUES-LED PLANNING APPROACH}

It is quite obvious from empirical studies (Reimer et. al., 2014) that new spatial challenges are rendering new approaches, concepts and tools to be tested. Frequently dominating 'neoliberal ideology' in the planning process 'economization' of planning - leads to the market orientation that mainly supports the powered initiatives of private developers and makes planners' work insignificant with respect to general public. In some places it may lead to 'first come, first served' approach or 'bypassing' regulations in planning and decisionmaking, e.g. regarding new complex development initiative out of urban containment. Olesen (2013) argues that neoliberalization forces to think in different ways about consensus-driven strategic spatial planning and the usage of a relational spatial vocabulary. 'Adversarial practice' exists where planning practice involves or is characterised by conflict or opposition (Greek case Reimer et. al., 2014, p. 165), but a 'pillar society' is characterised by sociopolitical families, religions, ideological and cultural dividing lines, which influence spatial developments by 'pillared' decision-making. These and some other examples ask for a reason to identify a 'catalysts of problem solving' and 'change or values agents' to introduce them in the planning debates and practices as well as to improve the planning traditions and promote best possible spatial solutions.

It is possible to distinguish among various planning doctrines. Some topical concepts such as 'resilience', 'inclusiveness', etc. need criteria to be measured and then used for studies and projects. For this purpose a VLP approach could be promoted. Social value of planning is questioned if relating to east European and north-west European systems/practices (Reimer et. al., 2014, p. 10). Formal and informal planning as well as conformance and performance principles have been explored by Faludi (2000) and Janin Ravolin (2008). 'Soft' and 'hard' spaces in planning research take significant place. Functional principles of spatial delimitation increasingly prevail over territorial spatial delimitations. It is generally recognised that national governments should promote activities to improve governance and gain from collective ways of decision-making to be explored and properly institutionalised (Reimer et. al., 2014, pp. 14-15).

"Intrinsic logic" of the specific places often refers to the context-dependent and differentiated forms of planning practice (Getimis 2012). Drawing on the works of Gualini $(2004,2006)$ on rescaling planning power, "experimental regionalism" tests new 'spatial and institutional rationales'. Innovative planning practices usually were introduced within a consensus-oriented planning style, 
however, and the changes concerning policy styles are very slow (Reimer et. al., 2014, pp. 15-16).

Introduction of VLP approach based on consolidated new knowledge from stakeholders' experience and empirical evidence will help better understand and guide the relevant processes and their effects in specific territories based on the identified values (outcome of expertise) and attitudes (stakeholders' preferences), thus avoiding such problems as, for example, unplanned urban sprawl, environmental/landscape fragmentation and damage, unequally populated areas, remarkable differences in income, insolvent territories, etc. It is argued that due to implementation of the new approach within the proposed framework will lead to improved regional and local land use policies and thus better territorial governance, developing more inclusive and resilient territories for the benefit of entrepreneurship, society and nature. Innovation activities will be recognised, for example, when applying developed methodological guidelines in the planning process. Complex yet significant relationships between the values and preferences of the stakeholders in relation to land use and development are to be assessed.

Feasibility of introduction of the VLP approach into spatial planning practice may be seen when capitalising on relevant outcome of recent comparative analysis of transformations of spatial planning systems and practices in selected European countries over the past 20 years. The main conclusions from country cases show that, for example, in Denmark spatial planning has become more fragmented and heterogeneous, and related to it socio-economic and political context changed dramatically, which, in effect, means that the challenges and opportunities faced, together with the values and the mind-sets of the actors involved, cannot realistically be compared (Reimer et. al., 2014, p. 40); in Finland, apart from the need for institutional reforms, better instruments for integrated cross-sector planning coupled with two-way evaluation and continuous monitoring of urban and regional development with relevant indicators of sustainability are required (Reimer et. al., 2014, p. 56); in the Dutch system economic development is the main priority of spatial planning, however, national planning has not taken on a balanced development as one of the key characteristics (Reimer et. al., 2014, p. 76); in Germany the principle of modern territorial governance consists in the premise that soft forms of communication and consensus-building should be used as much as possible, but hard forms of binding goals and hierarchical control should be used as much as necessary (Reimer et. al., 2014, p. 105); in France the scope of planning has broadened from physical planning to institutional design, the methods have evolved from quite static (e.g. zoning) to dynamic (processoriented) and planners need to develop new skills as the emphasis on public participation is growing progressively (Reimer et. al., 2014, p. 124); in Italy there have been considerable changes to the original conforming model, bringing in performance-oriented practices and strategic planning approaches (Reimer et. al., 2014, p. 145); in Greece, despite traditional features of planning based on command and control policy instruments, the hierarchical governance and adversarial planning practices, various citizen movements and environmental NGOs brought various environmental considerations into central and local planning agendas, along with the demands for more openness and participation in 
planning decisions (Reimer et. al., 2014, p. 165); in Flanders the Flemish structure planning and land-use planning have been reoriented towards the protection of private property, however, recent debates can initiate new trajectories towards a new more or less coherent spatial societal project and new concomitant planning instruments (Reimer et. al., 2014, p. 185); in the United Kingdom a planning practice requires bringing together sound technical knowledge with an understanding of what local communities value, and there are continuing assumptions that the public interest is best served through applying such concepts as urban containment, the compact city and heritage conservation, planners should be well aware that the planning system and its concepts are manipulated by powerful interests, whether in business or politics, e.g. regarding the protection of critical natural capital, ecosystems services and local energy generation (Reimer et. al., 2014, p. 209); in the Czech Republic within 'value-free' planning, which is still conceived as a technique rather than a conceptual effort, while inherent doctrine of planning is missing, the planners do not create visions for future development or future landscape changes, they are considered as the executive arms for the planning process, rather than experts, who should be listened to (Reimer et. al., 2014, p. 233); in Turkey there is a lack of analytical tools and knowledge base, inter-disciplinarity and professional diversity, and as institutions should seek for and demand reliable knowledge and expertise as well as concentrate this on the issues like better integration of local actors into the strategic spatial planning system, likewise the planners should develop new skills and learn new knowledge (Reimer et. al., 2014, p. 252); and in Poland, even if the legal requirements are in place, a progress in the development of new policy instruments is variable and the influence of adopted plans and policies is clearly limited, moreover, transparent, accountable decision-making processes and clear political leadership at the urban and regional levels that could support effective planning still should be developed (Reimer et. al., 2014, p. 274).

It is recognised that the systems and practices in other European countries should be studied using the proposed methodological framework. Considering relatively recent historical evolution of the Baltic countries - Estonia, Latvia and Lithuania, it is necessary to develop a model and involve/use not only the focuses of transformation (countries and use of particular comparable criteria) and additional countries added to those representing four 'ideal types' (countries by type), but also the main phases and turning points when setting a time perspective (by years) and considering the restoration of independence in 1990 or since the first evidence of formal beginning of planning practice (e.g. Planning Law of 1994 in Latvia). Therefore, more complete study outcome due to 'path-dependent evolutions' could be reached and discussed.

Comparisons of evidence-based findings from all the countries are concerned with significant changes and key challenges, which indicate the necessity and feasibility to introduce the VLP approach to improve first of all spatial planning practices in many countries. Overall conclusions show that besides the institutional system of spatial planning that has developed notable powers of persistence, the informal planning instruments are increasingly gaining significance in tackling the challenges associated with spatial planning aims. The 
need for simplification of the planning systems involves also discourse regarding flexible planning, with the prerogative of effectiveness and competitiveness, as finding balance between "efficiency" and "legitimacy" was and still is a major concern in all planning systems (Reimer et. al., 2014, p. 280). This balance has been better achieved in planning systems with integrated participatory mechanisms. The rise of 'territorial governance' is associated with multi-actor and multi-level governance arrangements that enhance new networks of 'bargaining' and 'arguing'. Moreover, a common trend concerning the changes of policy style can be seen leading to emergence or enhancement of consensus features of the planning process and 'opening' of planning processes to new stakeholders. However, 'arguing' networks are lagging behind or do not even exist. Therefore, even in the countries with a long tradition in communicative planning cultures, e.g. Finland and Denmark, there is a lack of deliberative participation and 'arguing' networks, and mainstream statutory planning systems have not been radically transformed (Reimer et. al., 2014, pp. 294-295). In all examined countries a common shift towards a more strategic, development-oriented spatial planning has been observed, which is quite strongly influenced by the Europeanization principles and directives, in particular - territorial cohesion, competitiveness, sustainability, and coordination. Introduction of the VLP approach may help not only 'to absorb' implementation of these principles and directives, but also may shift from 'value-free' culture, where planners serve the needs of specific parties and do not meet sustainable development goals. The approach may be useful for coexistence of consensus-oriented features with command and control planning styles. Spatial planning systems have always had to balance values and goals that are not always compatible or even contradictory. It is argued that even the prerogative of 'market-led planning' requires a new flexibility to be able to respond effectively both to macro-economic imperatives and to the tailored local growth needs, which emerge in non-statutory functional area, i.e. 'soft spaces' with 'fuzzy boundaries' (Reimer et. al., 2014, p. 299). Considering the rescaling of planning power, it is also obvious that various functional problems referring to local and regional employment, travel to work areas, housing areas, river catchment areas, risk areas, peri-urban areas, city agglomerations and cross-border areas cannot be solved within the predetermined rigid boundaries of existing administrative planning bodies. Thus, 'new soft spaces' with flexible boundaries emerge, and planning practices adapted to specific needs are experimented with and can be supported with the VLP approach. Moreover, 'change agents' may be communities or networks of authoritative claims to knowledge, advocacy coalitions or 'principled issue networks' (Reimer et. al., 2014, p. 301) with common beliefs, values and identities, policy networks bound together by common goals for planning arrangements.

It can be concluded here that by introducing the VLP approach and thus providing a potential to improve spatial planning practice with consensus-oriented planning style the mainstream statutory planning approach will not be substituted. Therefore, these two can coexist and even fruitfully supplement each other. 


\section{CONCLUSION}

Recent evolution of planning cultures, its substantial changes during last twenty years and prospective continuation quite clearly argue in favour of the VLP approach to be developed and implemented to improve spatial planning.

The main conclusions show conceptual considerations of the VLP approach, as it will help to improve the relevant practice and assess its effects in specific territories based on identified values and attitudes. The established scientifically sound framework would promote not only the internalisation of negative externalities, but also enable identifying the synergy that would enhance the balanced socio-economic and environmental impact and improve governance in the territory.

Planning, implementation of plans and decision-making strive for collaborative learning by understanding the values of land-related resources, their most efficient usage and development and management of sustainable communities, therefore discourse regarding consensus-oriented planning style should be promoted. It would lead to win-to-win solutions in the planning practices, however, planners as professionals need: (1) to change their profiles properly to adapt to the introduction of new planning approach, (2) to be more skilled, capable and powered enough in their positions to face new challenges, and (3) to shift their roles from 'executive arms' towards 'competent advisers'.

Topicality, objectives and outcomes of the relevant comparative studies emphasise appropriateness and feasibility of introduction of VLP approach. Accordingly, it is proposed to develop methodological solutions for better and more efficient land use, improved collaboration between urban and rural municipalities (communities), and increased cross-sectoral cooperation that would enable sustainable development and promote employment when implementing new planning approach. Furthermore, recommendations for innovative assessment tools to be applied when introducing the proposed planning approach should be developed.

\section{ACKNOWLEDGMENT}

This work has been supported by the European Regional Development Fund within the Activity 1.1.1.2 "Post-Doctoral Research Aid" of the Specific Aid Objective 1.1.1 "To increase the research and innovative capacity of scientific institutions of Latvia and the ability to attract external financing, investing in human resources and infrastructure" of the Operational Programme "Growth and Employment" No. 1.1.1.2/VIAA/1/16/161.

\section{REFERENCES}

Auziņš, A. (2013). Evaluation Methodology of Land Use Efficiency in Land Management (Summary of the doctoral thesis, Riga Technical University).

CEC - Commission of the European Communities. (1997). The EU Compendium of Spatial Planning Systems and Policies. Luxembourg: Office for Official Publications of the European Communities. Retrieved from https://publications.europa.eu/lv/publication-detail/-/publication/059 fcedf-d453-4d0d-af36-6f7126698556 
COMMIN. (2007). Comparison of Planning Systems and BSR Glossaries. BSR INTERREG IIIB project. Retrieved November 15, 2015, from http://commin.org

ESPON. (n. d., a). Comparative Analysis of Territorial Governance and Spatial Planning Systems in Europe. Retrieved November 9, 2017, from https://www.espon.eu/programme/ projects/espon-2020/applied-research/comparative-analysis-territorial-governance-and

ESPON. (n. d., b). Comparative Analysis of Territorial Governance and Spatial Planning Systems in Europe. Retrieved November 9, 2017, from https://www.espon.eu/programme/ projects/espon-2020/applied-research/comparative-analysis-territorial-governance-and

Faludi, A. (Ed.). (2008). European Spatial Research and Planning. Lincoln Institute of Land Policy.

Faludi, A. (2000). The Performance of Spatial Planning. Planning Practice and Research, 15(4), 299-318. https://doi.org/10.1080/713691907

Fürst, D. (2009). Planning cultures en route to a better comprehension of "planning processes"? In J. Knieling and F. Othengrafen (Eds.), Planning Cultures in Europe: Decoding Cultural Phenomena in Urban and Regional Planning (pp. 23-38). Farnham: Ashgate.

Getimis, P. (2012). Comparing Spatial Planning Systems and Planning Cultures in Europe: The Need for a Multi-Scalar Approach. Planning Practice and Research, 27(1), 25-40. https://doi.org/10.1080/02697459.2012.659520

Gualini, E. (2004). Regionalization as "Experimental Regionalism": The Rescaling of Territorial Policy-Making in Germany. International Journal of Urban and Regional Research, 28(2), 329-353. https://doi.org/10.1111/j.0309-1317.2004.00522.x

Gualini, E. (2006). The Rescaling of Governance in Europe: New Spatial and Institutional Rationales. European Planning Studies, 14(7), 881-904. https://doi.org/10.1080/09654310500496255

Janin Rivolin, U. (2008). Conforming and Performing Planning Systems in Europe: An Unbearable Cohabitation. Planning Practice and Research, 23(2), 167-186. https://doi.org/10.1080/02697450802327081

Janin Rivolin, U. (2012). Planning Systems as Institutional Technologies: A Proposed Conceptualization and the Implications for Comparison. Planning Practice and Research, 27(1), 63-85. https://doi.org/10.1080/02697459.2012.661181

Larsson, G. (2006). Spatial Planning Systems in Western Europe: An Overview. Amsterdam, Netherlands: IOS Press.

Larsson, G. (2010). Land Management as Public Policy. University Press of America.

Olesen, K. (2013) The Neoliberalisation of Strategic Spatial Planning. Planning Theory, 13(3), 288-303. https://doi.org/10.1177/1473095213499340

Petersen, B., \& Snapp, S. (2015). What is sustainable intensification? Views from experts. Land Use Policy, 46, 1-10. https://doi.org/10.1016/j.landusepol.2015.02.002

Randolph, J. (2012). Environmental Land Use Planning and Management (2nd revised ed.). Island Press.

Reimer, M., Getimis, P. \& Blotevogel, H. (Eds.). (2014). Spatial Planning Systems and Practices in Europe: A Comparative Perspective on Continuity and Changes. Routledge. 


\section{AUTHORS' SHORT BIOGRAPHIES}

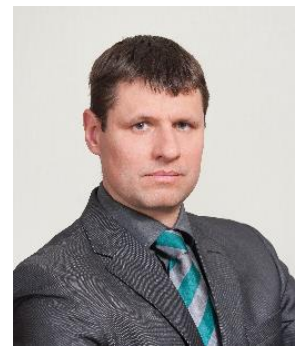

Armands Auzin̄š is an associate professor of the Faculty of Engineering Economics and Management, Riga Technical University (Latvia). He holds the degree of Doctor of Economic Sciences. He is a scientific expert in management and economic sciences of the Latvian Council of Science. He is a participant of the European Academy of Land Use and Development and a member of the Latvian Association of Land Surveyors (FIG member). $\mathrm{He}$ has more than 15 years of consulting experience in land use management. His main research topic is methodology development for land use evaluation and values-led planning approach for sustainable land use and development. He is lecturing on land management and has a number of publications in journals and conference proceedings. He has participated in international research projects. His research interests include land use management, institutional and real estate economics, and evaluation techniques.

ORCID iD: http://orcid.org/0000-0002-4341-5201

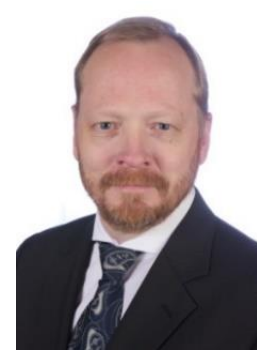

Jānis Viesturs, Mg. oec., is an assistant researcher of the Faculty of Engineering Economics and Management, Riga Technical University (Latvia). Janis Viesturs has more than 20 years of experience in real property management, development, transactions and due diligence process. He is lecturing the course "International Real Property Transactions". Since 2015 he has participated in scientific conferences, congresses and workshops. His research interests are real property definition, international and national real property transactions, different real property registration systems, real property due diligence process and real property management. He is a doctoral student at Riga Technical University.

ORCID iD: http://orcid.org/0000-0002-0267-1858 